\title{
A Hydroponic Seedling Assay for Resistance to Cephalosporium Stripe of Wheat
}

\author{
Christina Cowger and Christopher C. Mundt, Department of Botany \& Plant Pathology, Oregon State Univer- \\ sity, Corvallis 97331-2902
}

\begin{abstract}
Cowger, C., and Mundt, C. C. 1998. A hydroponic seedling assay for resistance to Cephalosporium stripe of wheat. Plant Dis. 82:1126-1131.

A procedure was developed to rate winter wheat seedlings approximately 20 days old for resistance to Cephalosporium stripe, a vascular wilt caused by the soilborne fungus Cephalosporium gramineum. Seedlings were inoculated after 12 to 15 days of growth in liquid culture in controlled-environment chambers, then assessed for disease symptoms at 7 to 8 days post-inoculation. Disease severity was assayed by measuring chlorophyll in the youngest fully expanded leaf, using a chlorophyll meter. Four replicated trials tested a total of 12 winter wheat cultivars, including both hard red cultivars from the U.S. Southern Plains and soft white winter cultivars from the U.S. Pacific Northwest. With one exception, the procedure consistently ranked cultivars correctly, according to field performance, as moderately resistant or susceptible. Jagger, a moderately resistant, hard red Kansas wheat, was ranked with susceptible cultivars in one of three trials.
\end{abstract}

Additional keywords: Hymenula cerealis, Triticum aestivum

Cephalosporium stripe is a monocyclic, vascular wilt disease of winter wheat and other grasses (6). The causal agent, Cephalosporium gramineum Nisikado \& Ikata (Hymenula cerealis Ell. \& Ev.), is a soilborne, facultative fungal parasite (6). It enters wheat roots in the fall and winter $(13,23)$, colonizes the vascular system, and causes leaf striping, stunting, and premature ripening of heads (whiteheads) in the spring and summer $(6,9)$. The fungus oversummers as a saprophyte in wheat debris and can remain viable in superficial wheat straw for up to 3 years (27).

Cephalosporium stripe inflicts substantial losses on winter wheat crops in the Pacific Northwest of the United States $(7,18)$. Currently, no fungicide is known to be effective against the pathogen, and effective cultural practices (burning of stubble, deep tillage, and delayed seeding) result in increased soil erosion (26). Repeated planting of moderately resistant cultivars can reduce both the incidence and severity of Cephalosporium stripe $(8,20)$. The development of host resistance currently offers the best hope for control of the disease in the Pacific Northwest.

Breeding programs are hampered in identifying resistance to Cephalosporium stripe in the field by long trial times and variability in symptom expression. Host

Corresponding author: C. Cowger

E-mail: cowgerc@bcc.orst.edu

Accepted for publication 21 June 1998.

Publication no. D-1998-0731-01R

(C) 1998 The American Phytopathological Society reaction to the disease is highly dependent on environment, and the ranking of cultivars can vary substantially from year to year (8), rendering multiple trials necessary. Therefore, rapid initial screening of cultivars under controlled conditions is desirable.

Until now, most controlled-environment work with Cephalosporium stripe has been done with vernalized, adult wheat plants, requiring a total trial time of 5 to 6 months (12; T. Murray, personal communication). In one study, winter wheat seedlings were assayed for Cephalosporium stripe resistance in controlled-environment chambers (25). That screening procedure distinguished highly susceptible from highly resistant lines, but was found less useful for lines with intermediate susceptibility.

Our work shows that measurable symptoms can be produced in wheat seedlings grown in liquid culture in growth chambers, and that the severity of those symptoms corresponds to the resistance ratings of adult plants in the field. Our method distinguishes cultivars with moderate resistance from those that are susceptible, and allows characterization of resistance within 1 month after germination of seeds.

\section{MATERIALS AND METHODS}

Biological materials. We evaluated eight soft white winter wheat cultivars from the Pacific Northwest (PNW; Idaho, Oregon, and Washington) and four hard red winter wheat cultivars from the U.S. Southern Great Plains (SGP; Kansas and Texas). The 12 cultivars vary in their field reactions to $C$. gramineum (Table 1 ).

Together, the cultivars we used display the full range of resistance present among winter wheat cultivars grown commercially in Oregon and Kansas. Among PNW cultivars, Madsen is consistently the most resistant to Cephalosporium stripe, and Malcolm the least resistant. In Kansas, the cultivars Sturdy and Plainsman V are used in field experiments as the susceptible and resistant checks, respectively $(4,5)$. Plainsman $\mathrm{V}$ is the cultivar with greatest proven resistance to Cephalosporium stripe under Kansas conditions; Jagger apparently possesses equal or greater resistance $(4,5)$.

Published susceptibility ratings are unavailable for some of the cultivars used in this study, and for others are contradictory to the results of our field experiments. Indeed, apparent cultivar susceptibility can vary with environment and year (8). From field data collected over multiple years, we believe the cultivars discussed here can all be separated into the categories "moderately resistant" (MR) and "susceptible" (S), although ranking within those categories is only possible in some cases. Under Cephalosporium stripe pressure, the soft white winter cultivars designated in Table 1 as MR generally have a percentage of whiteheads at least $50 \%$ lower than those rated $\mathrm{S}$ when tested in Oregon (C. Mundt, unpublished data).

The isolate of $C$. gramineum was obtained in July 1995 from infected wheat in a field in Pendleton, Oregon, that had been infested in 1993 with an isolate obtained from the Palouse region of eastern Washington.

Experimental design. Cultivars were tested in four trials conducted in October 1995 (Table 2), November 1995 (Table 1), February 1996 (Table 1), and March 1996 (Table 1). The experiment was conducted in a randomized complete block design, with four blocks in the second and third trials and three blocks in the first and fourth trials. The experimental unit was a container of plants (described below); containers were placed in several growth chambers. There were one or two blocks per growth chamber, depending on chamber size.

In the second and third trials, each container was planted half with one cultivar and half with another. Cultivars were paired randomly, and randomization was conducted separately for each replication. In the first and fourth trials, each container held only one cultivar.

Plant growth. Seeds were surface-disinfested in $0.525 \% \mathrm{NaOCl}$ solution for 15 min. Seeds were pre-germinated for 1 to 2 days in distilled water that was continu- 
ously aerated with an aquarium bubbler. The seeds were then placed individually in slots in a styrofoam holder lined underneath with plastic mesh so that, during germination, the roots protruded down through the mesh into an approximately 1$\mathrm{cm}$ layer of damp, sterilized sand beneath the holders (Fig. 1). During germination, the upper surface of the styrofoam was covered with thoroughly moistened paper towels, and the entire apparatus was enveloped in black plastic.

After 4 to 5 days of germination, the holders with seedlings were removed from the sand and the roots were rinsed in distilled water. The holders with seedlings were transferred to plastic containers measuring approximately $24.5 \mathrm{~cm}$ in height, $21 \mathrm{~cm}$ in width, and $8.5 \mathrm{~cm}$ in depth (Tupperware Corp., Orlando, FL), and painted black to inhibit algal growth. The containers were filled with $4,500 \mathrm{ml}$ of a modified Hoagland's solution (19) adjusted to pH $5.0 \pm 0.1\left(4 \mathrm{mM} \mathrm{Ca}\left[\mathrm{NO}_{3}\right]_{2}, 2\right.$ $\mathrm{mM} \mathrm{MgSO}_{4}, 4 \mathrm{mM} \mathrm{KNO}, 0.435 \mathrm{mM}$ $\left[\mathrm{NH}_{4}\right]_{2} \mathrm{SO}_{4}, \quad 0.5 \quad \mathrm{mM} \quad \mathrm{KH}_{2} \mathrm{PO}_{4}, \quad 2 \mu \mathrm{M}$ $\mathrm{MnSO}_{4}, 0.3 \mu \mathrm{M} \mathrm{CuSO}_{4}, 0.8 \mu \mathrm{M} \mathrm{ZnSO}$, $30 \mu \mathrm{M} \mathrm{NaCl}, 0.0143 \mu \mathrm{M}\left[\mathrm{NH}_{4}\right]_{6} \mathrm{Mo}_{7} \mathrm{O}_{2}, 10$ $\mu \mathrm{M} \mathrm{H}_{3} \mathrm{BO}_{3}$, and $10 \mu \mathrm{M}$ Fe-EDTA).

Seedlings were then grown in growth chambers (approximately $3 \times 10^{8} \mathrm{erg} \cdot \mathrm{m}^{-2} \cdot \mathrm{s}^{-1}$ ) at $20 \pm 2^{\circ} \mathrm{C}$ for 19 to 23 days, and the nutrient solutions were aerated with aquarium bubblers. After 3 days, each container was thinned to 20 seedlings.

Inoculation. $C$. gramineum was grown in $80 \%$-strength (345 g/liter) potato-dextrose broth. The fungus was grown first in flasks containing $1,800 \mathrm{ml}$ of broth, which were then used to inoculate carboys, each of which contained 18 liters of broth. The broth in flasks and carboys was continu- ously and vigorously agitated with sterile air. After about 5 days, the broth was strained through cheesecloth to remove mycelium. Conidia were separated from the broth by centrifugation. The conidia were resuspended in a small volume of distilled water or nutrient solution, and their concentration was determined using a hemacytometer.

After 12 to 15 days of growth in liquid medium, each inoculated container of wheat seedlings received conidia and fresh nutrient solution in the proportions needed to generate a suspension of approximately $1 \times 10^{8}$ conidia $/ \mathrm{ml}$. In three of the trials, uninoculated control treatments were included, and they received fresh nutrient solution only. The solution was adjusted to $\mathrm{pH} 5.0 \pm 0.1$, using $\mathrm{NaOH}$ and $\mathrm{HCl}$, and roots were suspended in it by floating the styrofoam holders on the surface.

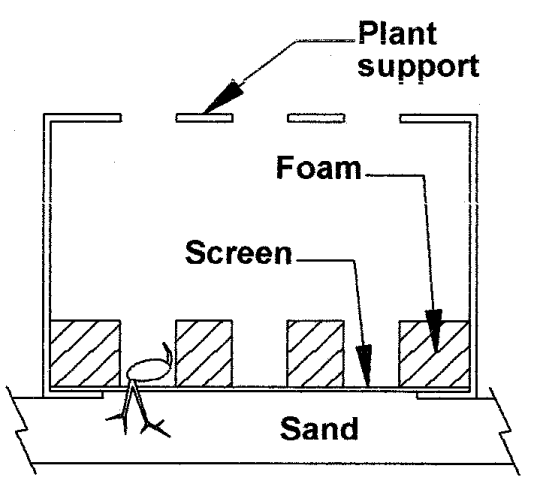

Fig. 1. Cross-sectional view of holders in which seeds were germinated over sand and seedlings were grown in liquid culture. Each holder had slots for 35 seeds; after transfer to liquid culture, holders were thinned to 20 seedlings each.

Table 2. Chlorophyll readings of 1-month-old winter wheat cultivars inoculated and not inoculated with Cephalosporium gramineum in liquid culture

\begin{tabular}{lccc}
\hline & \multicolumn{3}{c}{ Chlorophyll $^{\mathbf{x}}$} \\
\cline { 2 - 4 } Cultivar $^{\mathbf{y}}$ & Uninoculated & Inoculated & Reaction $^{\mathbf{z}}$ \\
\hline Madsen & $38.1 \mathrm{a}$ & $37.2 \mathrm{a}$ & MR \\
Lambert & $34.5 \mathrm{~b}$ & $33.1 \mathrm{~b}$ & MR \\
MacVicar & $32.4 \mathrm{~cd}$ & $28.6 \mathrm{c}$ & $\mathrm{S}$ \\
Stephens & $34.0 \mathrm{bc}$ & $27.6 \mathrm{~cd}$ & $\mathrm{~S}$ \\
Gene & $31.5 \mathrm{~d}$ & $25.3 \mathrm{~d}$ & $\mathrm{~S}$ \\
LSD & 1.91 & 3.08 &
\end{tabular}

${ }^{\mathrm{x}}$ Readings taken with a chlorophyll meter in four places along the youngest fully expanded leaf of each plant and averaged to produce one measurement per plant. Values are means of four replications of approximately10 plants each. Means within a column with the same letter are not significantly different $(P=0.05)$ according to Fisher's protected least significant difference (LSD) test.

y All cultivars from the Pacific Northwest.

${ }^{\mathrm{z}}$ Field reaction; $\mathrm{MR}=$ moderately resistant; $\mathrm{S}=$ susceptible.

Table 1. Chlorophyll readings from three trials of winter wheat seedlings inoculated with Cephalosporium gramineum in liquid culture

\begin{tabular}{|c|c|c|c|c|c|c|c|c|c|c|c|c|c|}
\hline \multirow[b]{3}{*}{ Cultivarw } & \multirow[b]{3}{*}{ Origin $^{x}$} & \multirow[b]{3}{*}{ Rct. $^{y}$} & \multicolumn{11}{|c|}{ Chlorophyll readingu } \\
\hline & & & \multicolumn{3}{|c|}{ Noninoculated $^{\mathrm{v}}$} & \multicolumn{4}{|c|}{ Inoculated } & \multicolumn{4}{|c|}{ Difference } \\
\hline & & & Nov. & Feb. & Comb & Nov. & Feb. & Mar. & Comb. & Nov & Feb & Comb & Rank $^{w}$ \\
\hline Madsen & PNW & MR & $36.3 \mathrm{a}$ & $37.6 \mathrm{a}$ & $37.0 \mathrm{a}$ & $32.8 \mathrm{a}$ & $30.5 \mathrm{a}$ & $32.0 \mathrm{a}$ & $31.7 \mathrm{a}$ & 3.5 & 7.1 & 5.3 & 3 \\
\hline Plainsman V & SGP & MR & $29.8 \mathrm{bcd}$ & $32.5 \mathrm{bc}$ & $31.2 b c$ & $27.5 \mathrm{~b}$ & $24.6 \mathrm{bc}$ & $27.0 \mathrm{~b}$ & $26.3 \mathrm{~b}$ & 2.3 & 7.9 & 5.1 & 2 \\
\hline Newton & SGP & MR & $31.7 \mathrm{~b}$ & $32.4 \mathrm{c}$ & $32.0 \mathrm{~b}$ & $25.7 \mathrm{bc}$ & $25.3 \mathrm{~b}$ & $27.0 \mathrm{~b}$ & $25.9 \mathrm{bc}$ & 6.0 & 7.1 & 6.6 & 5 \\
\hline Jagger & SGP & MR & $28.8 \mathrm{~cd}$ & $31.1 \mathrm{~cd}$ & $30.0 \mathrm{~cd}$ & $25.2 \mathrm{bcd}$ & $24.8 \mathrm{bc}$ & $21.8 \mathrm{~d}$ & $24.1 \mathrm{~cd}$ & 3.6 & 6.3 & 5.0 & 1 \\
\hline Gene & PNW & $\mathrm{S}$ & $28.8 \mathrm{~cd}$ & $31.1 \mathrm{~cd}$ & $30.0 \mathrm{~cd}$ & $23.0 \mathrm{cde}$ & $22.4 \mathrm{bc}$ & $22.4 \mathrm{~cd}$ & $22.6 \mathrm{de}$ & 6.0 & 9.7 & 7.9 & 8 \\
\hline Stephens & PNW & $S$ & $31.1 \mathrm{bc}$ & $32.1 \mathrm{c}$ & $31.6 \mathrm{~b}$ & 23.1 cde & $21.8 \mathrm{bc}$ & $22.3 \mathrm{~cd}$ & $22.4 \mathrm{de}$ & 8.0 & 10.3 & 9.2 & 9 \\
\hline Sturdy & SGP & S & $27.6 \mathrm{~d}$ & $30.9 \mathrm{~cd}$ & $29.2 \mathrm{~d}$ & $23.3 \mathrm{cde}$ & $22.8 \mathrm{bc}$ & $20.5 \mathrm{~d}$ & $22.4 \mathrm{de}$ & 4.3 & 8.1 & 6.2 & 4 \\
\hline MacVicar & PNW & $\mathrm{S}$ & $29.1 \mathrm{~cd}$ & $29.2 \mathrm{~d}$ & $29.2 \mathrm{~d}$ & $22.3 \mathrm{de}$ & $22.5 \mathrm{bc}$ & $20.5 \mathrm{~d}$ & $21.9 \mathrm{e}$ & 6.8 & 6.7 & 6.8 & 6 \\
\hline Malcolm & PNW & $\mathrm{S}$ & $28.7 \mathrm{~cd}$ & $29.7 \mathrm{~d}$ & $29.2 \mathrm{~d}$ & $21.5 \mathrm{e}$ & $21.3 \mathrm{c}$ & $20.5 \mathrm{~d}$ & $21.2 \mathrm{e}$ & 7.2 & 8.4 & 7.8 & 7 \\
\hline Lewjain ${ }^{z}$ & PNW & MR & $\ldots$ & $\ldots$ & $\ldots$ & $\ldots$ & $23.6 \mathrm{bc}$ & $25.6 \mathrm{bc}$ & $\ldots$ & & & & \\
\hline $\operatorname{Rod}^{\mathrm{z}}$ & PNW & MR & $\ldots$ & $\ldots$ & $\ldots$ & $\ldots$ & $\ldots$ & $26.9 \mathrm{~b}$ & $\ldots$ & & & & \\
\hline Lambert $^{\mathrm{z}}$ & PNW & MR & $\ldots$ & $\ldots$ & $\ldots$ & $\ldots$ & $\ldots$ & $26.1 \mathrm{~b}$ & $\ldots$ & & & & \\
\hline LSD & & & 2.52 & 2.38 & 1.65 & 3.31 & 3.81 & 3.38 & 1.96 & & & & \\
\hline
\end{tabular}

u Readings taken with a chlorophyll meter in four places along the youngest fully expanded leaf of each plant and averaged to produce one measurement per plant. Lower values indicate less chlorophyll content and greater disease severity. Values are means of four replications of approximately 10 plants each in the first two trials, and three replications of approximately 20 plants each in the third trial. Means within a column followed by a letter in common are not significantly different $(P=0.05)$ according to Fisher's protected least significant difference (LSD) test.

${ }^{v}$ Noninoculated treatments were not present in the March trial.

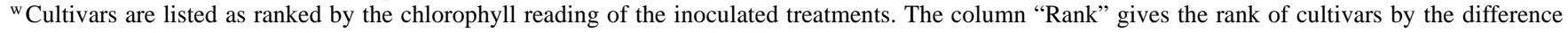
between noninoculated and inoculated chlorophyll values, where 1 signifies the least chlorophyll loss and 9 the greatest.

${ }^{x}$ PNW $=$ Pacific Northwest soft white cultivar; SGP $=$ Southern Great Plains hard red cultivar.

y Field reaction; $\mathrm{MR}=$ moderately resistant; $\mathrm{S}=$ susceptible.

${ }^{\mathrm{z}}$ Cultivars tested in one or two trials only. 
Germinability of the inoculum was determined by diluting it to approximately $10^{2}$ conidia $/ \mathrm{ml}$, plating $0.5 \mathrm{ml}$ on potatodextrose agar, and counting germinated spores after approximately 7 days of incubation at $13^{\circ} \mathrm{C}$. Germination averaged $45 \%$.

Plants were maintained in growth chambers with their roots bathed in the inoculum suspension for 7 to 8 days. Solution $\mathrm{pH}$ was returned to $5.0 \pm 0.1$ daily for 4 days after inoculation.

Symptom assessment. At 7 or 8 days after inoculation, yellowing or striping of leaves, or both, was assessed by measuring chlorophyll content with a SPAD-502 chlorophyll meter (Minolta Camera Co., Ltd., distributed by Spectrum Technologies, Inc., Plainfield, IL). The youngest fully expanded leaf was measured in four places, spaced approximately equally from base to tip of the leaf, and the measurements were averaged to yield one reading per plant.

The SPAD-502 meter measures peak chlorophyll absorbance at $650 \mathrm{~nm}$, and nonchlorophyll absorbance (e.g., cell walls) at $940 \mathrm{~nm}$. A microprocessor calculates a SPAD value, which is proportional to the relative optical density, based on the ratio of absorbencies at the two wavelengths. Values reported correspond to the amount of chlorophyll present in a leaf; lower values indicate less chlorophyll, or more severe yellowing. Data from this meter correlate closely $\left(r^{2}=0.93\right)$ with standard destructive measurements of chlorophyll that are accurate to within $\pm 5 \%$ (15). The relationship between the destructive measurements and those made by the meter is curvilinear, with the rate of increase of SPAD values slowing slightly as chlorophyll concentration increases (15). Thus, the range of SPAD values that we obtained slightly understates the actual differences in chlorophyll concentration among our greenest and least-green seedlings.
Consistency in selection of the leaf to be measured was critical, since chlorophyll content varies considerably with leaf age in a given seedling, whether diseased or undiseased. A leaf was chosen for measurement when, inside its base, the tip of the next emerging leaf could be seen. If the next emerging leaf tip was not visible, or was already longer than approximately 3 $\mathrm{cm}$, either the plant was omitted from data collection or readings from the two leaves older and younger than an "ideally" aged leaf were averaged. Such averaged readings corresponded closely to those obtained from "ideal" leaves.

Infection by $C$. gramineum was confirmed by isolating the pathogen from infected plants following symptom assessment. Two plants from each of several randomly chosen treatments in each replication were sampled. Stem sections of approximately $5 \mathrm{~cm}$ were surface-disinfested in $0.525 \% \mathrm{NaOCl}$ solution for $90 \mathrm{~s}$, allowed to air-dry under a hood, and cut into $1.5-\mathrm{cm}$ segments. The segments were plated on $C$. gramineum selective medium (CGSM) as developed by Specht and Murray (21), and sequentially incubated 4 days at $5^{\circ} \mathrm{C}, 4$ to 5 days at $13^{\circ} \mathrm{C}$, and 7 to 10 days at $5^{\circ} \mathrm{C}$. On average, $C$. gramineum was recovered from $77 \%$ of treatments sampled. There was no association with host cultivar or replication among the segments from which $C$. gramineum was not recovered; most were overgrown by other fungi in the earlier experiments while the isolation technique was in development.

Comparison to adult plants in the field. To test the relevance of chlorophyll measurements as predictors of infection severity in adult plants, readings were taken on cultivars Madsen (moderately resistant) and Stephens (susceptible) at the milk stage in plots at the Columbia Basin Agricultural Research Center in Moro, Oregon. The plots had been inoculated in fall 1993, and the inoculum present in fall
1995 was what remained in the debris from the 1993 to 1994 winter wheat trial. Plots lay fallow during the 1994 to 1995 season, and were replanted in fall 1995.

In June 1996, 50 tillers of each cultivar were sampled in each of three plots in a randomized complete block design. Starting $1.5 \mathrm{~m}$ from the end of each plot, the first 50 tillers in a center row were selected. Chlorophyll was measured in flag leaves in the same manner as with seedlings, and the plants were tagged and numbered. The same plants were surveyed for height and the presence of whiteheads 12 days later. Symptoms of strawbreaker foot rot (causal agent $=$ Pseudocercosporella herpotrichoides), the other disease often associated with whiteheads in this wheatgrowing region, were not present in these plots, nor were insects that can cause whiteheads.

Chlorophyll was also measured in the flag leaves of plants at the milk stage in June 1996 in an experiment planted in a naturally infested commercial field near Moro, Oregon. The susceptible cultivar Stephens and the three moderately resistant cultivars Lambert, Rod, and Madsen were sampled. From each cultivar, 15 plants were selected blindly at 1-m intervals for measurement in each of four plots planted in a randomized complete block design. In the same plots, the percentage of culms expressing whiteheads or incipient whiteheads was visually estimated at the late milk-early dough stage, 15 days after the chlorophyll readings.

Plants protected from foliar diseases in field plots at the Hyslop Field Research Laboratory in Corvallis, Oregon, were assayed for flag leaf chlorophyll in May 1996 and May 1997, at the heading stage. The purpose was to test whether chlorophyll content ranks healthy adult plants in the same order as diseased plants. Cephalosporium stripe does not occur in western Oregon, where this field is located. In the

Table 4. Correlation of chlorophyll readings on winter wheat cultivars inoculated and not inoculated with Cephalosporium gramineum in liquid culture absence of Cephalosporium gramineum

\begin{tabular}{lccccc}
\hline & & \multicolumn{3}{c}{ Chlorophyll reading } & \\
\cline { 3 - 4 } Cultivar & Origin $^{\mathbf{y}}$ & Nov. & Feb. & Comb. & Reaction $^{\mathbf{z}}$ \\
\hline Madsen & PNW & $36.3 \mathrm{a}$ & $37.6 \mathrm{a}$ & $37.0 \mathrm{a}$ & MR \\
Lewjain & PNW & $\ldots$ & $34.9 \mathrm{~b}$ & $\ldots$ & MR \\
Newton & SGP & $31.7 \mathrm{~b}$ & $32.4 \mathrm{c}$ & $32.0 \mathrm{~b}$ & MR \\
Stephens & PNW & $31.1 \mathrm{bc}$ & $32.1 \mathrm{c}$ & $31.6 \mathrm{~b}$ & $\mathrm{~S}$ \\
Plainsman & SGP & $29.8 \mathrm{bcd}$ & $32.5 \mathrm{bc}$ & $31.2 \mathrm{bc}$ & MR \\
Gene & PNW & $29.0 \mathrm{~cd}$ & $32.1 \mathrm{c}$ & $30.6 \mathrm{bcd}$ & S \\
Jagger & SGP & $28.8 \mathrm{~cd}$ & $31.1 \mathrm{~cd}$ & $30.0 \mathrm{~cd}$ & MR \\
Sturdy & SGP & $27.6 \mathrm{~d}$ & $30.9 \mathrm{~cd}$ & $29.2 \mathrm{~d}$ & S \\
Malcolm & PNW & $28.7 \mathrm{~cd}$ & $29.7 \mathrm{~d}$ & $29.2 \mathrm{~d}$ & S \\
MacVicar & PNW & $29.1 \mathrm{~cd}$ & $29.2 \mathrm{~d}$ & $29.2 \mathrm{~d}$ & $\mathrm{~S}$ \\
LSD & & 2.52 & 2.38 & 1.65 & \\
\hline Reading & & & & & \\
\hline
\end{tabular}

${ }^{\mathrm{x}}$ Readings taken with a chlorophyll meter in four places along youngest fully expanded leaf of each plant and averaged to produce one measurement per plant. Lower values indicate greater disease severity. Values are means of four replications of approximately 10 plants each. Means within a column with the same letter are not significantly different $(P=0.05)$ according to Fisher's protected least significant difference (LSD) test.

y PNW = Pacific Northwest soft white cultivar; SGP = Southern Great Plains hard red cultivar.

${ }^{\mathrm{z}}$ Field reaction; $\mathrm{MR}=$ moderately resistant; $\mathrm{S}=$ susceptible.

\begin{tabular}{lll}
\hline Trial & All cvs. $^{\mathbf{w}}$ & No Madsen $^{\mathbf{x}}$ \\
\hline October & & \\
$R^{\mathrm{y}}$ & 0.93 & 0.78 \\
$P^{\mathrm{z}}$ & 0.0229 & 0.2166 \\
November & & \\
$R$ & 0.84 & 0.37 \\
$P$ & 0.0049 & 0.3714 \\
February & & \\
$R$ & 0.79 & 0.41 \\
$P$ & 0.0063 & 0.2733 \\
\hline
\end{tabular}

${ }^{w}$ Number of cultivars: 5 in October, 9 in November, and 10 in February. tant cultivar Madsen, which had a significantly greater chlorophyll rating than all other cultivars.

y Pearson correlation coefficient.

${ }^{\mathrm{z}}$ Probability, with $\mathrm{H}_{\mathrm{o}}: R=0$.
${ }^{x}$ Correlations excluding the moderately resis- 
first year, one plot each of six cultivars and two plots each of two other cultivars were sampled. Eight to nine plants were selected randomly and flag leaf chlorophyll was measured in the same manner as in previously described experiments. In the second year, measurements were taken in three plots each of six cultivars.

Growth-chamber experiments with different fungal isolates. Two additional growth-chamber experiments were conducted with seedlings to assess whether different isolates of $C$. gramineum would rank cultivars differently for resistance. These experiments were factorial, with cultivars and fungal isolates as the factors. The first experiment, which had three trials, used six of the cultivars previously mentioned (three each from the PNW and the SGP) and two fungal isolates (the isolate from Oregon already discussed and another isolate from Kansas). The second experiment had two trials. In it, eight cultivars (four each from the PNW and the SGP) were tested with two isolate mixes, one consisting of two isolates from Oregon and the other consisting of two isolates from Kansas. None of the four isolates in the second experiment had been used in the first.

Statistical analyses. Chlorophyll data were subjected to analysis of variance (ANOVA) for individual controlled-environment trials and across trials of a particular experiment. Separate analyses were conducted for readings of the uninoculated plants. Data analyzed were the mean chlorophyll readings for all plants of the same cultivar in a container (the experimental unit). Cultivar means were separated using Fisher's protected least significant difference (LSD) test $(P \leq 0.05)$. In addition, correlation between inoculated and uninoculated means was evaluated for the October, November, and February trials.

Data on chlorophyll, plant height, and whitehead data from the field trials were first averaged over all plants in a plot (the experimental unit), then subjected to ANOVA and means separation using Fisher's protected LSD test.

For the experiments comparing different fungal isolates, the mean of all homolo- gous host-pathogen combinations (cultivars and isolate or isolates from the same geographic region) was compared to the mean of all heterologous combinations (cultivars and isolate or isolates from different regions). The means were compared using linear contrasts.

\section{RESULTS}

Growth chamber trials. In each of the four trials, differences among inoculated cultivars were highly significant (respectively, $P \leq 0.0001, P \leq 0.0001, P \leq$ 0.0022 , and $P \leq 0.0001)$. Three trials (November, February, and March) were analyzed in combination, because they included nine cultivars in common and the trial $\times$ cultivar interaction was not significant $(P=0.7379)$ in the combined analysis; cultivar differences were highly significant $(P \leq 0.0001)$.

In each trial, cultivars usually ranked in accordance with their known field performance relative to each other (Tables 1 and 2). The five susceptible cultivars consistently ranked lowest, except where Jagger fell among them in the March trial. Jagger's field resistance is actually equal to or greater than that of Plainsman V $(4,5$, and $\mathrm{W}$. W. Bockus, personal communication).

One of the four trials placed susceptible and moderately resistant cultivars in separate groups at the 0.05 probability level (Table 2); the other three trials did not. In the combined analysis, the moderately resistant and susceptible groups were distinguished at the 0.05 probability level, except that Jagger (which ranked inconsistently among trials) bridged the two categories.

Chlorophyll differences among noninoculated plants in the October, November, and February trials were also highly significant $(P \leq 0.0004)$, although much of the variation was accounted for by that between Madsen and the other cultivars (Tables 2 and 3). Chlorophyll content ranked uninoculated and inoculated cultivars differently (Table 1 and 3). Correlation analysis of the three trials showed a positive correlation $(P<0.05)$ in the chlorophyll content of inoculated and uninoculated plants if the cultivar Madsen

Table 5. Chlorophyll levels and plant height data read in June 1996 from a field trial of winter wheat cultivars $^{\mathrm{w}}$ inoculated with Cephalosporium gramineum in Moro, Oregon ${ }^{\mathrm{x}}$

\begin{tabular}{lcclcc}
\hline & \multicolumn{2}{c}{ Madsen } & & \multicolumn{2}{c}{ Stephens } \\
\cline { 2 - 3 } \cline { 5 - 6 } & Chlorophylly & Height $(\mathbf{c m})^{\mathbf{z}}$ & & Chlorophylly & Height $(\mathbf{c m})^{\mathbf{z}}$ \\
\hline White head & $8.9 \mathrm{a}$ & $58.3 \mathrm{a}$ & & $9.3 \mathrm{a}$ & $64.3 \mathrm{a}$ \\
No white head & $29.1 \mathrm{~b}$ & $79.4 \mathrm{~b}$ & & $25.7 \mathrm{~b}$ & $77.0 \mathrm{~b}$ \\
\hline
\end{tabular}

${ }^{\mathrm{w}}$ Madsen, rated moderately resistant, and Stephens, susceptible.

${ }^{\mathrm{x}}$ Readings taken with chlorophyll meter in four places along flag leaf of each culm and averaged to produce one measurement per culm. Within a column, means with the same letter are not significantly different $(P=0.05)$ according to Fisher's protected least significant difference (LSD) test.

${ }^{y}$ Values are means of data collected on 50 culms of each cultivar in each of three replicated plots in a randomized, complete block experiment.

${ }^{\mathrm{z}}$ Culm height measured on same plants 12 days after chlorophyll measurement. Within a column, means with the same letter are not significantly different $(P=0.05)$ according to Fisher's protected LSD test.

was included in the analysis, but the correlations were lower and not significant $(P$ $>0.05$ ) if Madsen was omitted (Table 4). Madsen is moderately resistant to Cephalosporium stripe and had a chlorophyll content in liquid culture distinctly higher than that of other cultivars.

Comparison to adult plants in the field. Flag leaf chlorophyll readings cor-

Table 6. Chlorophyll levels and white head incidence from a 1996 winter wheat trial in a commercial field with naturally-occurring Cephalosporium gramineum inoculum near Moro, Oregon

\begin{tabular}{lcc}
\hline Cultivar & Chlorophyll $^{\mathbf{y}}$ & \% White heads $^{\mathbf{z}}$ \\
\hline Lambert & $36.9 \mathrm{a}$ & $4.4 \mathrm{c}$ \\
Madsen & $35.8 \mathrm{a}$ & $0.1 \mathrm{a}$ \\
Rod & $35.2 \mathrm{a}$ & $1.2 \mathrm{~b}$ \\
Stephens & $30.9 \mathrm{~b}$ & $33.9 \mathrm{~d}$ \\
LSD & 3.10 & 2.42 \\
\hline
\end{tabular}

${ }^{y}$ Readings taken with chlorophyll meter in four places along the flag leaf of each culm and averaged to produce one measurement per culm. Values are means of four plots in a randomized, complete block design, with 15 culms sampled at regular intervals in each plot. Measurements made 10 June (milk stage). Within a column, means with the same letter are not significantly different $(P=0.05)$ according to Fisher's protected least significant difference (LSD) test.

${ }^{\mathrm{z}}$ Percent culms with white heads, assayed 25 June (late milk/early dough stage). Reported values are back-transformed from log-transformed data used in means separation. Within a column, means with the same letter are not significantly different $(P=0.05)$ according to Fisher's protected LSD test.

Table 7. Flag-leaf chlorophyll ${ }^{\mathrm{w}}$ levels of undiseased $^{\mathrm{x}}$ winter wheat plants at heading stage in two years in Corvallis, Oregon

\begin{tabular}{|c|c|c|c|}
\hline \multirow[b]{2}{*}{ Cultivar } & \multicolumn{2}{|c|}{ Year } & \multirow[b]{2}{*}{ Ret. . $^{-}$} \\
\hline & 1996 & 1997 & \\
\hline Stephens & 48.7 & $47.1 \mathrm{a}$ & $\mathrm{S}$ \\
\hline Madsen & 46.7 & $43.6 \mathrm{~b}$ & MR \\
\hline MacVicar & 46.4 & $42.5 \mathrm{bc}$ & $\mathrm{S}$ \\
\hline Rod & 46.1 & $42.3 \mathrm{bc}$ & MR \\
\hline Malcolm $^{2}$ & 44.9 & $\ldots$ & $\mathrm{S}$ \\
\hline Gene & 42.0 & $41.6 \mathrm{c}$ & $\mathrm{S}$ \\
\hline Yamhill & 42.9 & $39.3 \mathrm{~d}$ & MR \\
\hline Lewjain $^{\mathrm{Z}}$ & 37.8 & $\ldots$ & MR \\
\hline LSD & & 1.92 & \\
\hline
\end{tabular}

${ }^{\text {w }}$ Readings taken with chlorophyll meter in four places along the flag leaf of each culm selected blindly and averaged to produce one measurement per culm. Values for 1996 are means of two plots for Lewjain $(39.0,36.5)$ and Stephens $(48.5,48.8)$, and one plot for the other cultivars. Values for 1997 are means of three replicated plots per cultivar. Means with the same letter are not significantly different $(P=0.05)$ according to Fisher's protected least significant difference (LSD) test.

x Plants sprayed to protect from foliar disease in a field where Cephalosporium stripe does not occur.

${ }^{\mathrm{y}}$ Field reaction; $\mathrm{MR}=$ moderately resistant; $\mathrm{S}$ $=$ susceptible.

${ }^{\mathrm{z}}$ Cultivars not present in 1997. 
related with the field symptoms of Cephalosporium stripe (Table 5). In the artificially inoculated Moro field trial, a low chlorophyll reading in the flag leaf was highly correlated with the later development of a whitehead $(P<0.0001)$ and with short culm stature $(P<0.0001)$.

Chlorophyll readings in the commercial wheat field with naturally-occurring inoculum clearly distinguished the susceptible cultivar from the three moderately resistant cultivars (Table 6).

By contrast, wheat free of Cephalosporium stripe in the field in Corvallis yielded flag-leaf chlorophyll readings at heading that did not rank plants according to susceptibility to Cephalosporium stripe (Table 7).

Growth-chamber experiments with different fungal isolates. Of interest in these experiments was whether isolates of C. gramineum from different regions would rank cultivars differently. This could be determined by inspecting the cultivar $x$ isolate interaction in the ANOVA (Table 8 for the first experiment; second experiment data not shown). In neither experiment was the interaction significant $(P=0.5481$ and $P=0.5121$, respectively), indicating that the isolates and isolate mixtures from the two regions did not interact differentially with the host cultivars tested.

No significant difference in chlorophyll was detected between homologous and heterologous combinations of host and pathogen in either the first experiment $(P=$ 0.360 ; Table 8$)$ or the second experiment $(P=0.588 ;$ data not shown $)$.

\section{DISCUSSION}

Wheat seedlings can be screened effectively under controlled conditions for resistance to Cephalosporium stripe. The chlorophyll content in the inoculated seedlings is easily quantified and in general is an accurate predictor of the field resistance of adult plants.

Differences in greenness among diseased plants do not simply mirror the variation among healthy plants, either juvenile or adult. Although there is some correspondence in chlorophyll content between inoculated and uninoculated seedlings in liquid culture, one cultivar, Madsen, accounts for most of this correlation. Madsen coincidentally possesses both relatively low susceptibility to Cephalosporium stripe and a high native chlorophyll content. The chlorophyll contents of inoculated and uninoculated plants are significantly correlated when Madsen is included; without Madsen, the correlation is insignificant. Further, our observations of field-grown, adult wheat indicate that chlorophyll content reflects Cephalosporium stripe susceptibility in diseased but not in undiseased plants.

Leaf chlorophyll content makes sense as a gauge of Cephalosporium stripe severity, because yellowing is one of the principal symptoms of a vascular wilt disease (3). Like other symptoms, such as flaccidity and necrosis (which were also observed in the inoculated wheat seedlings), yellowing probably results from water shortage due to occlusion of the vascular elements by the host's defensive products (gums, tyloses, and gels; 3). C. gramineum does produce a toxin, Graminin A (10), but its role in pathogenesis is controversial $(11,24)$.

All cultivars were properly grouped in each trial reported here, except Jagger in the March trial. In subsequent controlledenvironment trials using multiple inoculum types, Jagger also scored inappropriately as susceptible in three of eight trial $\times$ inoculum combinations (C. Cowger and C. Mundt, unpublished). Among the proposed phenotypes of resistance to Cephalosporium stripe (16) are those that limit ingress, such as resistance to rhizosphere acidity (22), and those that limit pathogen movement inside the host, such as crown morphology (14). Jagger's resistance may have a different physiological basis or may appear at a different developmental stage than that of the other cultivars we tested. The susceptible cultivar Stephens is a parent of Jagger.

The cultivar Madsen is moderately resistant and had a higher innate chlorophyll

Table 8. Analysis of variance of leaf chlorophyll content in six winter wheat cultivars inoculated with a single Southern Great Plains (SGP) or Pacific Northwest (PNW) isolate of Cephalosporium gramineum and grown in liquid culture in growth chambers ${ }^{\mathrm{y}}$

\begin{tabular}{lrcl}
\hline Source & df & Mean square & P \\
\hline Trial & 2 & 30.51 & 0.0129 \\
Block & 8 & 12.73 & 0.0687 \\
Cultivar & 5 & 332.43 & 0.0001 \\
Isolate & 1 & 35.95 & 0.0226 \\
Trial $\times$ isolate & 2 & 328.55 & 0.0001 \\
Trial $\times$ cultivar & 10 & 6.35 & 0.4908 \\
Cultivar $\times$ isolate & 5 & 5.38 & 0.5481 \\
Trial $\times$ cultivar $\times$ isolate & 10 & 4.21 & 0.7840 \\
Error & 88 & 6.67 & \\
\hline
\end{tabular}

${ }^{\mathrm{y}}$ Experiment with three trials.

${ }^{\mathrm{z}}$ Mean of homologous combinations $=24.2$; mean of heterologous combinations $=24.6$. Homologous $=$ all cultivar-isolate combinations from the same geographic region (e.g., SGP host and SGP inoculum). Heterologous = all cultivar-isolate combinations from different geographic regions (e.g., PNW host and SGP inoculum). Means not significantly different $(P=0.360)$. content than other cultivars in our controlled environment studies. Though we have not yet encountered the reverse case (i.e., a susceptible wheat cultivar with high innate chlorophyll content), such a cultivar could be falsely rated as moderately resistant to Cephalosporium stripe by our method. Thus, our procedures should be used only for initial screening, with the more promising cultivars being tested subsequently in the field.

While it would be helpful to draw a clearer line between moderately resistant and susceptible cultivars in single trials, ranking can be used to separate cultivars into two groups. With adequate replication and appropriate controls of known resistance, two trials should be sufficient to assign a new wheat line to the moderately resistant or susceptible class based on rank. Borderline cases, or inconsistent performers such as Jagger in our study, can be classed as moderately resistant. Moderately resistant lines must then be subjected to field tests to confirm growth chamber data.

We divided cultivars into two classes, susceptible and moderately resistant, based on consistent observations in the field. There are also quantitative differences within these two classes, but field data are inadequate to provide a definitive ranking for all of the cultivars discussed here. However, the results of our seedling tests bear some similarities to field observations (C. Mundt, unpublished). Malcolm is consistently among the most susceptible of Pacific Northwest cultivars that we have tested in the field in Oregon, while Madsen is usually the most resistant of those we have tested. Further, both Stephens and Malcolm are very susceptible in the field, but Malcolm consistently shows a slightly higher disease rating. Among moderately resistant cultivars, Madsen is more resistant than Rod, and limited observations have shown Rod to be more resistant than Lambert.

An alternative method for ranking cultivars would be by the difference in chlorophyll content between noninoculated and inoculated seedlings. This approach, which was our first in this study, is reasonable because it might reflect the amount of chlorophyll loss due to infection.

However, the resultant rankings (Table 1) for our data are no more satisfactory than those based simply on the chlorophyll content of inoculated seedlings. The range of uninoculated-inoculated differences among the nine cultivars screened was less (about 4 SPAD points) than the range among the inoculated ratings (about 10 SPAD points). In addition, Stephens would rank as more susceptible than Malcolm, while the reverse is in fact true in the field. One of the moderately resistant cultivars, Newton, would be grouped among the susceptible cultivars. Newton did not perform inconsistently among trials, while Jagger did, and so the ranking method that 
reflects that difference in variability seems preferable.

We suspect that ranking cultivars by the inoculated-uninoculated difference in chlorophyll readings is less useful than one would expect, in part because the difference is between two variables that are each subject to experimental error. Further, the relationship between the chlorophyll readings and chlorophyll content is non-linear (15), and new standard curves are required for each trial. Simple subtraction of SPAD values does not provide an accurate representation of chlorophyll loss due to disease. Thus, uninoculated treatments were omitted from our last trial in order to allow space for testing more cultivars, and such space considerations are likely to apply in most wheat breeding programs.

Various visual estimates of disease severity were also attempted, such as a severity score from 1 to 11 based on leaf striping (17), a count of the proportion of striped leaves, and estimation of yellowing for each experimental unit. None of the visual estimates produced a consistently satisfactory ranking, possibly because these techniques were developed for use with adult plants.

Our screening method has three advantages. First, a trial can be completed in under 30 days, as opposed to the period of 5 to 6 months needed for adult plants. Second, seedlings require less space than adult plants. These two factors will permit rapid initial screening of large numbers of new lines. Third, liquid culture ensures uniform distribution of inoculum around plant roots, and allows inoculation without artificial root wounding, which is necessary to produce substantial disease when plants inoculated with $C$. gramineum are grown in pots $(22,25)$.

In our experiments, isolates and isolate mixtures from Oregon and Kansas did not rank cultivars differently. These initial results provide no evidence of substantial pathogenic variability or the existence of virulence sensu Vanderplank in this fungus. In order to be sure that single isolates are adequate for controlled-environment screening, similar experiments should be conducted with a larger number of $C$. gramineum isolates and wheat cultivars.

Finally, our research addresses two aspects of the biology of Cephalosporium stripe. First, while it may contribute to disease, freezing of roots (2) is unnecessary for infection of wheat by $C$. gramineum, as has been noted by other workers $(1,23)$. The fungus consistently penetrates the roots of seedlings maintained at about $20^{\circ} \mathrm{C}$. Second, it would appear that juvenile and adult plants share one or more traits conferring resistance. Thus, in wheat, resistance is perhaps at least partially a physiological phenomenon and not conditioned solely by the morphology of adult plants.

\section{ACKNOWLEDGMENTS}

We thank B. Bockus, T. Murray, and C. Love for assistance with biological materials; F. Crowe and D. Smiley for their helpful reviews of the manuscript; the Oregon Wheat Commission for its financial support; J. Lewontin for assistance in developing research equipment, performing statistical analyses, and preparation of the figure; and $\mathrm{L}$. Cohnstaedt, D. Coyle, M. Hoffer, K. Kovar, and J. Mathis for their technical support.

\section{LITERATURE CITED}

1. Anderegg, J. C., and Murray, T. D. 1988. Influence of soil matric potential and soil $\mathrm{pH}$ on Cephalosporium stripe of winter wheat in the greenhouse. Plant Dis. 72:1011-1016.

2. Bailey, J. E., Lockwood, J. L., and Wiese, M. V. 1982. Infection of wheat by Cephalosporium gramineum as influenced by freezing of roots. Phytopathology 72:1324-1328.

3. Beckman, C. H. 1987. The Nature of Wilt Diseases of Plants. APS Press, St. Paul, MN.

4. Bockus, W. W. 1994. Reaction of selected winter wheat cultivars to Cephalosporium stripe, 1994. Bio. Cult. Tests 10:112.

5. Bockus, W. W. 1997. Reaction of selected winter wheat cultivars to Cephalosporium stripe, 1996. Bio. Cult. Tests 12:109.

6. Bruehl, G. W. 1957. Cephalosporium stripe disease of wheat. Phytopathology 47:641649.

7. Bruehl, G. W. 1968. Ecology of Cephalosporium stripe disease of winter wheat in Washington. Plant Dis. Rep. 52:590-594.

8. Bruehl, G. W., Murray, T. D., and Allan, R. E. 1986. Resistance of winter wheats to Cephalosporium stripe in the field. Plant Dis. 70:314-316.

9. Johnston, R. H., and Mathre, D. E. 1972. Effect of infection by Cephalosporium gramineum on winter wheat. Crop Sci. 12:817-819.

10. Kobayashi, K., and Ui, T. 1977. Graminin A, a new toxic metabolite from Cephalosporium gramineum Nisikado \& Ikata. J. Chem. Soc. Chem. Commun. 21:774.

11. Kobayashi, K., and Ui, T. 1979. Phytotoxicity and antimicrobial activity of Graminin A, produced by Cephalosporium gramineum, the causal agent of Cephalosporium stripe disease of wheat. Physiol. Plant Pathol. 14:129-133.

12. Love, C. S., and Bruehl, G. W. 1987. Effect of soil $\mathrm{pH}$ on Cephalosporium stripe in wheat. Plant Dis. 71:727-731.

13. Mathre, D. E., and Johnston, R. H. 1975. Cephalosporium stripe of winter wheat: infection processes and host response. Phytopathology 65:1244-1249.

14. Mathre, D. E., and Johnston, R. H. 1990. A crown barrier related to Cephalosporium stripe resistance in wheat relatives. Can. J. Bot. 68:1511-1514

15. Monje, O. A., and Bugbee, B. 1992. Inherent limitations of nondestructive chlorophyll meters: a comparison of two types of meters. HortScience 27:69-71.

16. Morton, J. B., and Mathre, D. E. 1980. Identification of resistance to Cephalosporium stripe in winter wheat. Phytopathology 70:812-817.

17. Morton, J. B., Mathre, D. E., and Johnston, R. H. 1980. Relation between foliar symptoms and systemic advance of Cephalosporium gramineum during winter wheat development Phytopathology 70:802-807.

18. Murray, T. D., Walter, C. C., and Anderegg, J. C. 1992. Control of Cephalosporium stripe of winter wheat by liming. Plant Dis. 76:282286.

19. Rhue, R. D. 1976. The time-concentration interaction of $\mathrm{Al}$ toxicity in wheat root meristems. Ph.D. thesis, Oregon State University, Corvallis.

20. Shefelbine, P. A., and Bockus, W. W. 1989 Decline of Cephalosporium stripe by monoculture of moderately resistant winter wheat cultivars. Phytopathology 79:11271131.

21. Specht, L. P., and Murray, T. D. 1989. Sporulation and survival of conidia of Cephalosporium gramineum as influenced by soil $\mathrm{pH}$, soil matric potential, and soil fumigation. Phytopathology 79:787-793.

22. Specht, L. P., and Murray, T. D. 1990. Effects of root-wounding and inoculum density on Cephalosporium stripe in winter wheat. Phytopathology 80:1108-1114.

23. Stiles, C. M., and Murray, T. D. 1996. Infection of field-grown winter wheat by Cephalosporium gramineum and the effect of soil pH. Phytopathology 86:177-183.

24. Van Wert, S. L., and Fulbright, D. W. 1986. Pathogenicity and virulence of Cephalosporium gramineum is independent of in vitro production of extracellular polysaccharides and graminin A. Physiol. Mol. Plant Pathol. 28:299-307.

25. Van Wert, S. L., Ravenscroft, A. V., and Fulbright, D. W. 1984. Screening wheat lines as seedlings for resistance to Cephalosporium gramineum. Plant Dis. 68:1036-1038.

26. Veseth, R., Miller, B., Guy, S., Wysocki D., Murray, T., Smiley, R., and Wiese, M. 1993. Managing Cephalosporium stripe in conservation tillage systems. Pacific Northwest Conserv. Tillage Hdbk. Series 4:17.

27. Wiese, M. V., and Ravenscroft, A. V. 1975. Cephalosporium gramineum populations in soil under winter wheat cultivation. Phytopathology 65:1129-1133. 